\title{
Risk patterns of lung cancer mortality in northern Thailand
}

\author{
Apinut Rankantha 1,2, Imjai Chitapanarux ${ }^{3,4,5}$, Donsuk Pongnikorn ${ }^{6}$, Sukon Prasitwattanaseree ${ }^{2}$, Walaithip Bunyatisai ${ }^{2}$, \\ Patumrat Sripan ${ }^{3,4,5}$ and Patrinee Traisathit ${ }^{2,7^{*}}$
}

\begin{abstract}
Background: Over the past decade, lung cancers have exhibited a disproportionately high mortality and increasing mortality trend in Thailand, especially in the northern region, and prevention strategies have consequently become more important in this region. Spatial analysis studies may be helpful in guiding any strategy put in place to respond to the risk of lung cancer mortality in specific areas. The aim of our study was to identify risk patterns for lung cancer mortality within the northern region of Thailand.

Methods: In the spatial analysis, the relative risk (RR) was used as a measure of the risk of lung cancer mortality in 81 districts of northern Thailand between 2008 and 2017. The RR was estimated according to the Besag-York-Mollié autoregressive spatial model performed using the OpenBUGS routine in the R statistical software package. We presented the overall and gender specific lung cancer mortality risk patterns of the region using the Quantum Geographic Information System.

Results: The overall risk of lung cancer mortality was the highest in the west of northern Thailand, especially in the Hang Dong, Doi Lo, and San Pa Tong districts. For both genders, the risk patterns of lung cancer mortality indicated a high risk in the west of northern Thailand, with females being at a higher risk than males.

Conclusions: There was distinct geographical variation in risk patterns of lung cancer mortality in Thailand. Differences could be related to differences in risk factors such as ground-based radon and air pollution. This study provides a starting point for estimating the spatial pattern of the risk of lung cancer mortality and for examining associations between geographic risk factors and lung mortality for further studies.
\end{abstract}

Keywords: Lung cancer, Mortality, Relative risk, Besag-York-Mollié

\section{Background}

Lung cancer is the leading cause of cancer-related mortality worldwide, and from 1990 to 2015, it was the most common cause of cancer mortality in 113 countries [1-3]. Thailand is one of those countries in which lung cancer has been the leading cause of mortality and healthcare burden compared to other cancer types, especially in the northern region [4-6]. Of all the regions in Thailand, the northern part ranks first in mortality rate caused by lung cancer and in addition, has the

\footnotetext{
* Correspondence: patrinee@gmail.com; patrinee.t@cmu.ac.th

${ }^{2}$ Department of Statistics, Faculty of Science, Chiang Mai University, Chiang Mai, Thailand

${ }^{7}$ Center of Excellence in Bioresources for Agriculture, Industry and Medicine, Faculty of Science, Chiang Mai University, Chiang Mai, Thailand

Full list of author information is available at the end of the article
}

highest mortality rate compared to other types of cancer $[4,5,7]$.

Over the past few decades, a considerable number of studies have been conducted to investigate factors associated with the occurrence, treatment, and outcomes of lung cancer in northern Thailand, such as demographic characteristics (including hereditary genetic mutations, gender, and geographic location), environmental hazards (such as exposure to indoor radon, smoke, and air pollution), patient health status and behavior, and healthcare providers' characteristics [8-17]. All of these factors might be contributing to the variations in cancer incidence, diagnosis, and outcomes [18]. Measuring the spatial distributions of diseases could help describe the possible determinants of disease occurrence or the outcome of healthcare interventions such as the aforementioned

(c) The Author(s). 2018 Open Access This article is distributed under the terms of the Creative Commons Attribution 4.0 International License (http://creativecommons.org/licenses/by/4.0/), which permits unrestricted use, distribution, and reproduction in any medium, provided you give appropriate credit to the original author(s) and the source, provide a link to the Creative Commons license, and indicate if changes were made. The Creative Commons Public Domain Dedication waiver (http://creativecommons.org/publicdomain/zero/1.0/) applies to the data made available in this article, unless otherwise stated. 
factors [19-21]. Moreover, spatial incidence patterns have been used to explore injuries and non-communicable disease incidences as these conditions are the result of interactions between behaviors, lifestyles, and the environment related to residential area and geographical differences [22-26].

Focusing on Chiang Mai province, the high-risk districts have a problem with high air pollution from particulate matter with a diameter smaller than $10 \mu \mathrm{m}$ (PM10) in northern Thailand [16, 27]. Moreover, this area is surrounded by high mountains that block diffusion and redirect airflow, thereby exacerbating air pollution accumulation along the foothills of the mountains [28-30]. In addition, urban development has been linked to the occurrence of lung cancer and leading to death $[31,32]$. The findings in [11] indicate that the urban growth in Chiang Mai province has had a tendency to increase over time while air quality has simultaneously declined. In addition, the risk patterns of lung cancer mortality have been found to be different geographically between males and females [26, 33, 34].

Small-area geographic data recommended when studying the magnitude of geographical health inequality [35-37]. In Thailand, small-areas studies have been rare, studies such as Aungkulanon et al. [4] which presented geographical patterns of lung cancer mortality using the standardized mortality ratio (SMR). The SMR represents the ratio of the observed and expected number of lung cancer mortalities for the total population. The SMR is a reliable risk measure for large geographical regions but may be unreliable for small areas [38]. The relative risk (RR) from the well-known Bayesian spatial model may overcome the problem of SMR [39-42].

The aim of this study was to identify risk patterns of lung cancer mortality across 81 districts spanning the six northern provinces of Thailand, specifically Chiang Mai, Chiang Rai, Phrae, Phayao, Lampang, and Lamphun. The method consists of using a well-known Bayesian spatial model to estimate the relative risk at the district level. The analysis was performed for both genders combined, and separately to obtain gender-specific estimates of the relative risk.

\section{Methods}

\section{The study area}

In this registry-based study, we focused on data from 81 districts within 6 provinces of the northern region of Thailand: Chiang Mai, Chiang Rai, Lampang, Lamphun, Phayao, and Phrae (Fig. 1). The median population size of the districts was 50,132 (range 11,025-229,033), of which the numbers of males and females were 24,346 (range 5735-110,167) and 25,843 (range 5290-122,063), respectively.

\section{Data collection}

We used data on lung cancer mortality from the Chiang Mai Cancer Registry, Faculty of Medicine, Chiang Mai University and the Lampang Cancer Registry, Lampang Cancer Hospital, that covered population-based cancer in Northern Thailand. Moreover, data collection was completed adequately and the completeness of the data was satisfactory for our study [43]. The participants in this study were 10,468 adults ( $>15$ years old) diagnosed with cancer of the lung (coded as International Classification of Diseases version 10 (ICD-10) C33-34) between 1 January 2008 and 31 December 2014 who then subsequently died from any cause between 1 January 2008 to 1 July 2017. The population census database from the Official Statistics Registration Systems, Department of Provincial Administration, Thailand, was used as the denominator for calculating age- and gender-specific mortality rates divided into 18 age groups $(0-4,5-9, \ldots, 80-$ $84,85+$ ) and by gender for the study area.

In this study, the observed number of deaths was derived from the number of deaths of people previously diagnosed with lung cancer from any cause during the study period in the 81 districts for the overall spatial analysis. For the spatial analysis by gender, the observed number of deaths by gender in each district was derived in the same way as for the overall spatial analysis. According to the coded data at the district level, the median number of observed cases per district was 100 (range 9-469), of which the median number of males was 57 (range 9-266) and that of females was 39 (range $0-203$ ). The expected number of cases in each district was calculated by taking the specific mortality rates of lung cancer and multiplying the population at the midpoint of the study periods for each district broken down into the same strata. The population data were likewise drawn from the Official Statistics Registration Systems, Department of Provincial Administration, Thailand.

\section{Statistical analyses}

In the spatial analysis, the observed number of deaths $Y_{i}$ $(i=1, \ldots, 81)$ are assumed to follow an independent Poisson distribution given $\theta_{\dot{v}} Y_{i} \sim \operatorname{Poisson}\left(\theta_{i} E_{i}\right)$, which is the unknown relative risk in each district, and $E_{i}$, which is the expected number of cases [44]. The Besag-York-Mollié (BYM) model [45] used to estimate the relative risk of lung cancer mortality includes both spatial heterogeneity typically represented using the aggregated neighbors of each district and uncorrelated spatial heterogeneity as follows [42]:

$\log \left(\theta_{i}\right)=\alpha+u_{i}+v_{i}$, where $\alpha$ is the intercept of the relative risk, and $u_{i}$ and $v_{i}$ are the correlated and uncorrelated heterogeneity components, respectively. $u_{i}$ is assumed to apply the spatial correlation since the relative risk estimation in each $i$ is dependent on the neighboring 


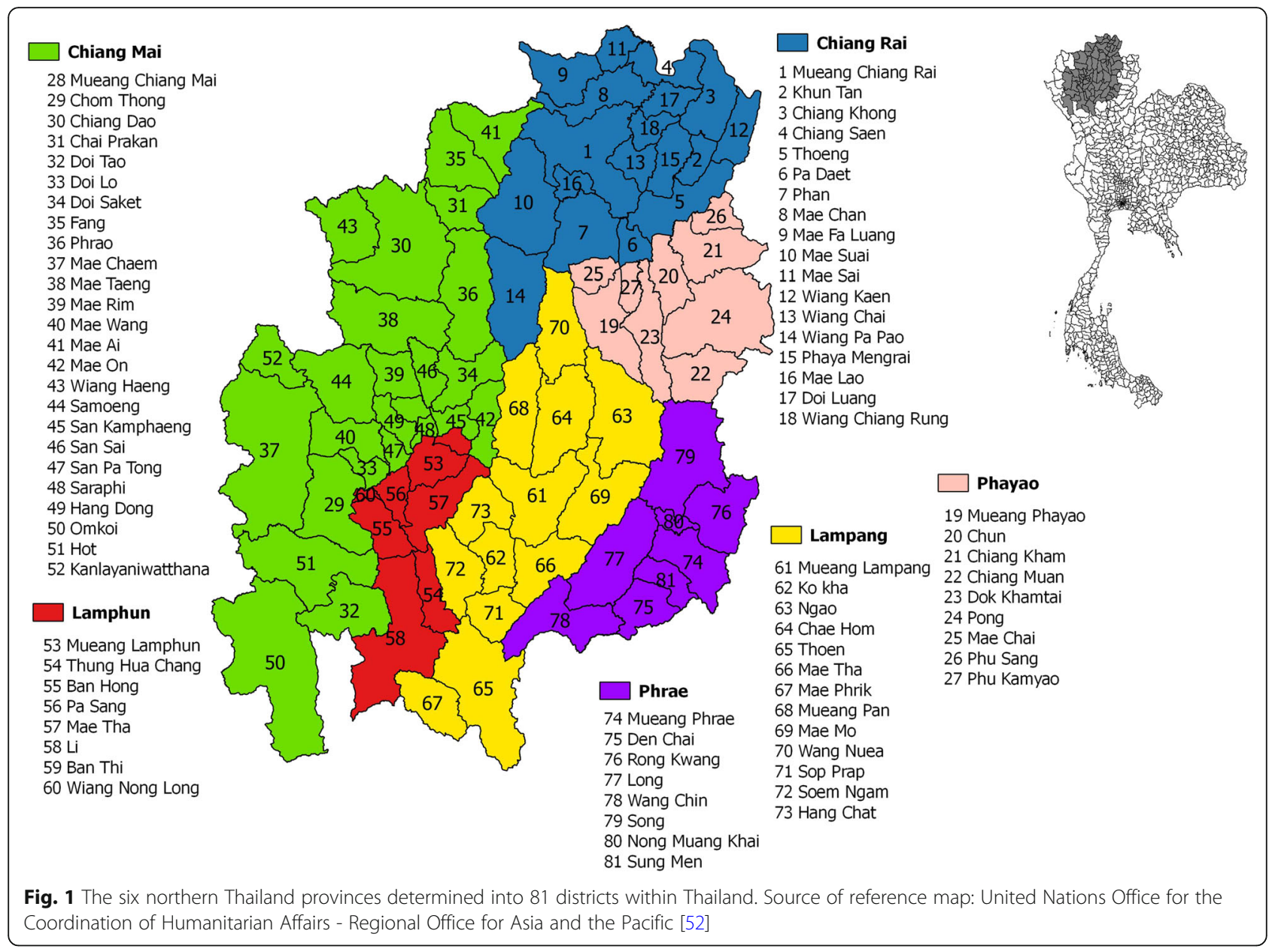

areas. The spatial structure is defined based on the adjacent neighbors of each district and is assumed to follow a Gaussian intrinsic autoregression. The $v_{i}$ uncorrelated heterogeneities are assumed to follow a normal distribution with zero mean (see $[44,46]$ for a more in-depth explanation of this component). This model was used to explore the RR spatial distribution for the risk of lung cancer mortality among the districts. The Gibbs sampling technique was implemented to estimate the parameters from the BYM model with the openBUGS [47] implementation in R syntax [48] presented by Gerber and Furrer [49] [see the $\mathrm{R}$ syntax in Additional file 1]. Furthermore, the deviance information criterion (DIC) for the model fitting result was calculated overall and by gender [50]. We estimated the RR of the lung cancer mortality for each district and its 95\% credible interval (CrI) with the intercept with

Table 1 The observed and expected number of lung cancer mortality in the six northern Thailand provinces

\begin{tabular}{|c|c|c|c|c|c|c|c|}
\hline & \multirow{3}{*}{$\begin{array}{l}\text { Total Population } \\
\text { Over } 15 \text { Years Old }\end{array}$} & \multicolumn{2}{|l|}{ Overall } & \multicolumn{4}{|c|}{ Gender } \\
\hline & & \multirow[b]{2}{*}{ Obs. } & \multirow[b]{2}{*}{ Exp. } & \multicolumn{2}{|l|}{ Male } & \multicolumn{2}{|c|}{ Female } \\
\hline & & & & Obs. & Exp. & Obs. & Exp. \\
\hline Chiang Mai & $1,294,412$ & 4141 & 3356 & 2390 & 1965 & 1751 & 1391 \\
\hline Chiang Rai & 935,620 & 2181 & 2265 & 1208 & 1350 & 973 & 915 \\
\hline Lampang & 644,750 & 1635 & 1811 & 1026 & 1063 & 609 & 748 \\
\hline Lamphun & 343,326 & 735 & 963 & 450 & 567 & 285 & 396 \\
\hline Phrae & 390,093 & 913 & 1062 & 580 & 604 & 333 & 458 \\
\hline Phayao & 410,391 & 863 & 1011 & 494 & 599 & 369 & 412 \\
\hline Total & $4,018,592$ & 10,468 & 10,468 & 6148 & 6148 & 4320 & 4320 \\
\hline
\end{tabular}

Obs Observed number, Exp Expected number 


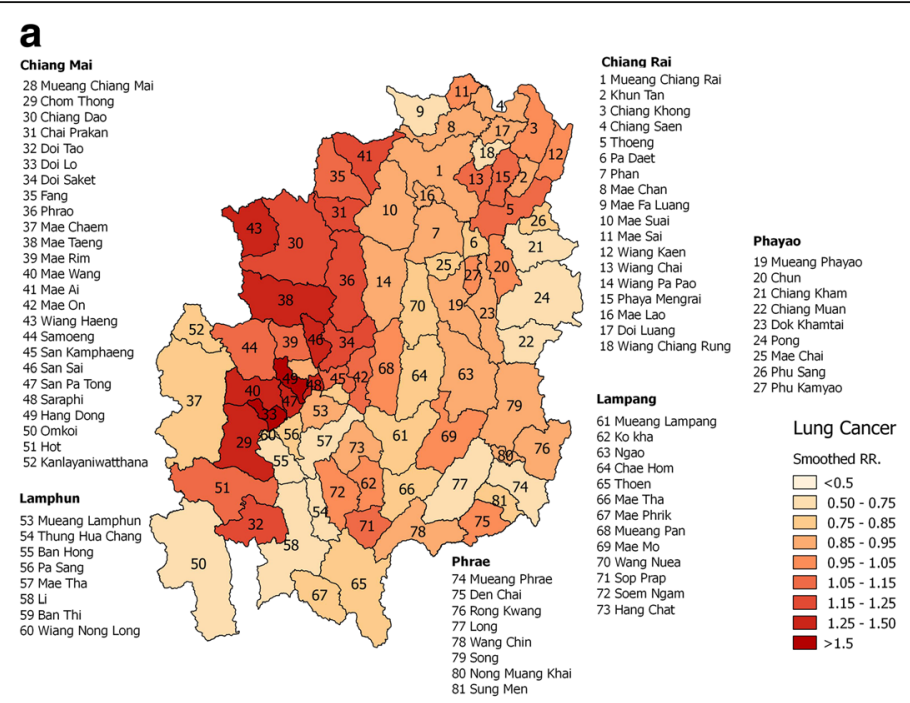

b
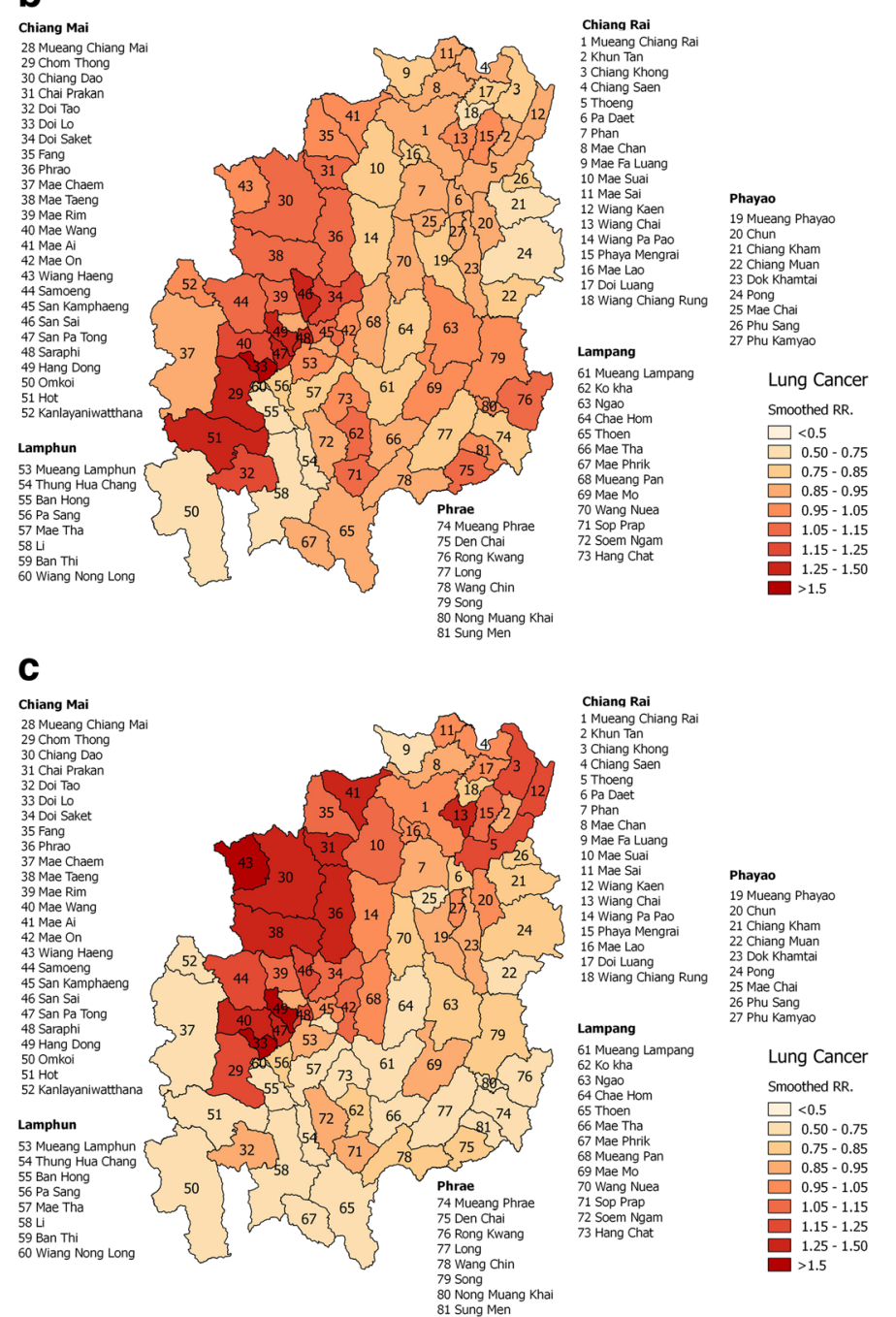

Fig. 2 Relative risk patterns of lung cancer mortality in the six northern Thailand provinces: a overall, $\mathbf{b}$ male, and $\mathbf{c}$ female. Source of reference map: United Nations Office for the Coordination of Humanitarian Affairs - Regional Office for Asia and the Pacific [52] 
the two random effects (spatial heterogeneity and uncorrelated spatial heterogeneity). The map of the risk patterns of lung cancer mortality for the 81 districts in 6 northern Thailand provinces was created using the Quantum Geographic Information System (QGIS) program version 2.8.1 [51]. The map used in this study were public shapefile dataset derived from United Nations Office for the Coordination of Humanitarian Affairs - Regional Office for Asia and the Pacific [52].

\section{Results}

\section{Characteristics}

The lung cancer mortality data during 2008-2017 in the 6 northern Thailand provinces consisted of 10,468 deaths of which 6148 (58\%) were male. We found that the largest number of cases occurred in Chiang Mai province (Table 1). The number of observed deaths from lung cancer were higher than the expected number for males in Chiang Mai province and for females in Chiang Rai province.

\section{The overall spatial analysis}

The overall DIC value from the BYM model was found to be 552.8. The RR of lung cancer mortality over the whole study ranged from 0.581-1.666 (Fig. 2a). The highest RR was found in Hang Dong district (Chiang Mai province) $[R R=1.666 ; 95 \% \mathrm{CrI}=1.611-1.729]$, then Wiang Chai district (Chiang Rai province) $[R R=1.140$; 95\% CrI $=1.103-1.097]$, Sop Prap district (Lampang province) $[\mathrm{RR}=1.089 ; 95 \% \mathrm{CrI}=1.053-1.130]$, Mueang Lamphun district (Lamphun province) $[\mathrm{RR}=0.942 ; 95 \%$ $\mathrm{CrI}=0.912-0.978]$, Den Chai district (Phrae province) $[R R=0.982 ; 95 \% \mathrm{CrI}=0.950-1.019]$, and Chun district (Phayao province) $[\mathrm{RR}=0.972 ; 95 \% \mathrm{CrI}=0.941-1.009]$, in that order (Table 2) [see RR of lung cancer mortality for all districts in Additional file 2]. The high-risk patterns of RR were found in Chiang Mai province (Fig. 2a).

\section{The spatial analysis by gender}

The DIC values from the BYM model for males and females were found to be 552.4 and 530.9 , respectively. The results of the spatial analysis by genders showed that the $\mathrm{RR}$ of lung cancer mortality for males over the whole study area ranged from $0.549-1.555$ and that of females ranged from $0.525-1.978$ (Fig. 2b, 2c). The results also show that in some provinces, the districts with the highest $R R$ of lung cancer mortality were different for males and females: the Doi Lo district for males $[R R=1.555$; $\mathrm{CrI}=$ 1.495-1.617] and Wiang Haeng for females $[R R=1.978$; $\mathrm{CrI}=1.894-2.066]$ in Chiang Mai province, the Sop Prap district for males $[R R=1.126$; $\mathrm{CrI}=1.083-1.171]$ and the Mueang Pan district for females $[\mathrm{RR}=1.048$; $\mathrm{CrI}=1.003-$ 1.094] in Lampang province, the Den Chai district for
Table 2 The three districts with the highest risk of lung cancer mortality in each province

\begin{tabular}{|c|c|c|c|}
\hline Province & District & $\mathrm{RR}$ & $95 \% \mathrm{Crl}$ \\
\hline \multicolumn{4}{|c|}{ Chiang Mai } \\
\hline & Hang Dong & 1.666 & $(1.611-1.729)$ \\
\hline & Doi Lo & 1.633 & $(1.580-1.695)$ \\
\hline & San Pa Tong & 1.467 & $(1.419-1.522)$ \\
\hline \multicolumn{4}{|c|}{ Chiang Rai } \\
\hline & Wiang Chai & 1.140 & $(1.103-1.183)$ \\
\hline & Thoeng & 1.057 & $(1.023-1.097)$ \\
\hline & Phaya Mengrai & 1.054 & $(1.020-1.094)$ \\
\hline \multicolumn{4}{|l|}{ Lampang } \\
\hline & Sop Prap & 1.089 & $(1.053-1.130)$ \\
\hline & Mae Mo & 1.010 & $(0.977-1.048)$ \\
\hline & Ko kha & 0.993 & $(0.960-1.030)$ \\
\hline \multicolumn{4}{|l|}{ Lamphun } \\
\hline & Mueang Lamphun & 0.942 & $(0.912-0.978)$ \\
\hline & Ban Thi & 0.800 & $(0.774-0.830)$ \\
\hline & Pa Sang & 0.782 & $(0.757-0.812)$ \\
\hline \multicolumn{4}{|l|}{ Phrae } \\
\hline & Den Chai & 0.982 & $(0.950-1.019)$ \\
\hline & Rong Kwang & 0.943 & $(0.912-0.978)$ \\
\hline & Nong Muang Khai & 0.907 & $(0.878-0.941)$ \\
\hline \multicolumn{4}{|l|}{ Phayao } \\
\hline & Chun & 0.972 & $(0.941-1.009)$ \\
\hline & Phu Kamyao & 0.952 & $(0.921-0.988)$ \\
\hline & Dok Khamtai & 0.894 & $(0.865-0.928)$ \\
\hline
\end{tabular}

$R R$ Relative risk, $\mathrm{Crl}$ Credible interval

males $[\mathrm{RR}=1.102 ; \mathrm{CrI}=1.060-1.146]$ and the Wang Chin district for females $[R R=0.814 ; C r I=0.779-0.850]$ in Phrae province, and the Mae Chai district for males $[R R=$ 0.941; $\mathrm{CrI}=0.905-0.978]$ and the Chun district for females $[R R=0.985 ; \mathrm{CrI}=0.943-1.029]$ in Phayao province. However, we found that the districts with the highest RR in Chiang Rai province (Wiang Chai for males $[R R=$ 0.979; $\mathrm{CrI}=0.941-1.018]$ and females $[\mathrm{RR}=1.311 ; \mathrm{CrI}=$ 1.255-1.369]) and Lamphun province (Mueang Lamphun for males $[R R=0.988 ; \mathrm{CrI}=0.950-1.027]$ and females $[R R=0.892 ; \mathrm{CrI}=0.854-0.931])$ were the same for both genders (Table 3) [see RR of lung cancer mortality by gender for all districts in Additional file 2]. The highest risk pattern of lung cancer mortality for males was found in southern Chiang Mai (Fig. 2b) whereas the highest risk pattern for females was found in northern Chiang Mai (Fig. 2c).

\section{Discussion}

Of the six northern Thailand provinces, the risk patterns of lung cancer mortality were the highest in the west (Chiang 
Table 3 The three districts with the highest risk of lung cancer mortality in each province by gender

\begin{tabular}{|c|c|c|c|c|c|c|}
\hline \multirow[t]{3}{*}{ Province } & \multicolumn{6}{|l|}{ Gender } \\
\hline & \multicolumn{3}{|l|}{ Male } & \multicolumn{3}{|l|}{ Female } \\
\hline & District & $\mathrm{RR}$ & (95\% Crl) & District & $\mathrm{RR}$ & (95\% Crl) \\
\hline \multicolumn{7}{|c|}{ Chiang Mai } \\
\hline & Doi Lo & 1.555 & $(1.495-1.617)$ & Wiang Haeng & 1.978 & $(1.894-2.066)$ \\
\hline & Hang Dong & 1.452 & $(1.396-1.509)$ & Hang Dong & 1.830 & $(1.753-1.912)$ \\
\hline & San Pa Tong & 1.424 & $(1.369-1.480)$ & Doi Lo & 1.508 & $(1.444-1.575)$ \\
\hline \multicolumn{7}{|c|}{ Chiang Rai } \\
\hline & Wiang Chai & 0.979 & $(0.941-1.018)$ & Wiang Chai & 1.311 & $(1.255-1.369)$ \\
\hline & Phaya Mengrai & 0.963 & $(0.926-1.002)$ & Chiang Khong & 1.232 & $(1.180-1.286)$ \\
\hline & Thoeng & 0.946 & $(0.910-0.984)$ & Thoeng & 1.161 & $(1.111-1.212)$ \\
\hline \multicolumn{7}{|l|}{ Lampang } \\
\hline & Sop Prap & 1.126 & $(1.083-1.171)$ & Mueang Pan & 1.048 & $(1.003-1.094)$ \\
\hline & Ko kha & 1.126 & $(1.082-1.171)$ & Soem Ngam & 0.922 & $(0.883-0.963)$ \\
\hline & Mae Mo & 1.034 & $(0.994-1.075)$ & Sop Prap & 0.921 & $(0.881-0.961)$ \\
\hline \multicolumn{7}{|l|}{ Lamphun } \\
\hline & Mueang Lamphun & 0.988 & $(0.950-1.027)$ & Mueang Lamphun & 0.892 & $(0.854-0.931)$ \\
\hline & Ban Thi & 0.938 & $(0.902-0.976)$ & Pa Sang & 0.848 & $(0.812-0.885)$ \\
\hline & Wiang Nong Long & 0.830 & $(0.798-0.863)$ & Wiang Nong Long & 0.779 & $(0.746-0.814)$ \\
\hline \multicolumn{7}{|l|}{ Phrae } \\
\hline & Den Chai & 1.102 & $(1.060-1.146)$ & Wang Chin & 0.814 & $(0.779-0.850)$ \\
\hline & Rong Kwang & 1.077 & $(1.036-1.120)$ & Song & 0.761 & $(0.728-0.795)$ \\
\hline & Nong Muang Khai & 1.009 & $(0.970-1.049)$ & Den Chai & 0.752 & $(0.720-0.786)$ \\
\hline \multicolumn{7}{|l|}{ Phayao } \\
\hline & Mae Chai & 0.941 & $(0.905-0.978)$ & Chun & 0.985 & $(0.943-1.029)$ \\
\hline & Chun & 0.917 & $(0.882-0.953)$ & Phu Kamyao & 0.953 & $(0.912-0.995)$ \\
\hline & Phu Kamyao & 0.912 & $(0.877-0.948)$ & Mueang Phayao & 0.911 & $(0.872-0.951)$ \\
\hline
\end{tabular}

RR Relative risk, $\mathrm{Crl}$ Credible interval

Mai) and lowest in the east (Phayao and Phrae) and south (Lamphun), which conforms to some of the findings of Aungkulanon et al. [4] who presented geographical distributions of cause-specific mortality (including liver cancer, lung cancer, chronic obstructive pulmonary disease, diabetes etc.). Regarding lung cancer, they found that the risk of mortality was the highest in Chiang Mai and the lowest in Phayao and Phrae, as did we. However, they found that the risk was high in Lamphun whereas it was low in our study. This disparity in the results was probably due to the differences in the design of the studies used to estimate the risk. In our study, the derived data were from people previously diagnosed with lung cancer who had died of any cause whereas their data were from the death certificates of people recorded as having died from lung cancer only. In addition, the BYM model can include unknown or unobserved risk factors that are related to the risk of lung cancer mortality [45], and thus may be more appropriate for spatial or geographical analyses in risk pattern studies.
The geographical patterns of risk of lung cancer mortality could be the result of environmental determinants. For instance, the Hang Dong and Doi Lo districts with the highest risk level $(R R \geq 1.50)$ are located in areas affected by high indoor radon and air pollution, which supports the hypothesis that these factors can affect the risk patterns of lung cancer mortality [24, 25, 31]. Future work should examine associations between environmental factors and lung cancer mortality.

In our study, different levels of risk of lung cancer mortality were found by geographical location, which might have been due to the geographical risk patterns in lung cancer mortality closely following those of lung cancer mortality incidence $[2,53]$. Therefore, the differences in the incidences between areas might have been affected by the geographical risk patterns of mortality. The spatial effects of previous studies such as the problem of high air pollution [16, 27], a geographical location characterized by high mountains [28-30], and increasing 
urban growth [11, 31, 32] might have been the reason for the high risk of lung cancer mortality in Chiang Mai province. A considerable number of studies on air pollution monitoring in the northern region of Thailand $[10,14,54]$ found that Chiang Mai was not the area with the highest air pollution level in this region, thus it seems that this might not be the only factor in the risk of death from lung cancer.

The analysis of the risk of lung cancer mortality by gender revealed that females were at a higher risk of lung cancer mortality than males, especially in districts within Chiang Rai province. This might have been due to the effect of the chewing of Miang (fermented wild tea leaves) and tobacco smoking (cigarettes and Khiyoh) $[12,55,56]$, in that the habit of females pursuing this pastime is higher than males [57]. Moreover, the severity of the stage of lung cancer at the time of diagnosis for females was higher than for males [7]. In addition, we found no significant differences in the risk patterns of lung cancer mortality by gender in Chiang Mai province, which exhibited high RR in the west of the study area for both genders. Although females had a higher risk of lung cancer mortality than males, the development of lung cancer preventative strategies should focus on both genders due to lung cancer being a healthcare burden and a leading cause of mortality in this region [4-7].

Our results may be useful to other researchers wishing to study the environmental factors related to lung cancer and other associated diseases. For example, researchers reporting the municipal distribution of bladder cancer mortality and attempting to adjust this spatial pattern for the prevalence of smoking used the estimated $R R$ values of lung cancer mortality as a surrogate for the prevalence of smoking using the BYM model to adjust for the RR of bladder cancer mortality [58]. Moreover, the random effects modeling with Bayesian spatial models, which represent the unknown risk factors and their estimation through the posterior distribution, could help to identify underlying causes for unknown risks.

\section{Conclusions}

In conclusion, we found that there was a high risk of lung cancer mortality in districts within Chiang Mai province, both overall and by gender. There was distinct geographical variation in risk patterns of lung cancer mortality in Thailand. Differences could be related to differences in risk factors such as ground-based radon and air pollution. However, our study was conducted to examine the spatial pattern of the risk of lung cancer mortality only. As such, this study provides a starting point for estimating the spatial pattern of the risk of lung cancer mortality and for examining associations between geographic risk factors and lung mortality for further studies.

\section{Additional files}

Additional file 1: Appendix 1. The OpenBugs syntax for the BYM model fitting. (DOCX $13 \mathrm{~kb}$ )

Additional file 2: Table S1. Relative risks of lung cancer mortality in each district. (DOCX $26 \mathrm{~kb}$ )

\section{Abbreviations}

BYM: Besag-York-Mollié.; Crl: Credible interval; DIC: The deviance information criterion; ICD: International Classification of Diseases; PM10: Particulate matter with a diameter of smaller than $10 \mu \mathrm{m}$; QGIS: The Quantum Geographic Information System; RR: Relative risk; SMR: Standardized mortality ratio

\section{Acknowledgements}

We thank the staff at Chiang Mai Cancer Registry (CMCR) and Cancer registry unit, Lampang Cancer Hospital for providing lung cancer mortality data used in this study. We also thank staff at Official Statistics Registration Systems,

Department of Provincial Administration, Thailand for population data used to calculate expected number.

\section{Funding}

This study did not receive any funding.

\section{Availability of data and materials}

This study use data from Chiang Mai Cancer Registry and Cancer registry unit, Lampang Cancer Hospital, Lampang, Thailand. Request for using their data should be addressed to Faculty of Medicine, Chiang Mai University Ethics Committees and The Research Ethics Committee of Lampang Cancer Hospital.

\section{Authors' contributions}

AR contributed in literature search, data collection, performed the data analyses and the writing of the manuscript. IC and DP contributed in study design, data collection and reviewing the manuscript. SP contributed in study design and reviewing the manuscript. WB and PS contributed in literature search and reviewing the manuscript. PT had primary responsibility for literature search, study design, performed the data analyses and the writing of the manuscript. All authors contributed to critical revisions of the manuscript and approved the final submitted version.

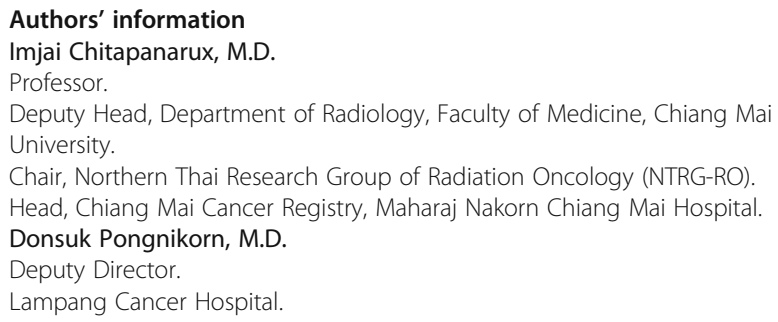

Ethics approval and consent to participate

This study was approved by The Research Ethics Committee, Faculty of Medicine, Chiang Mai University and The Research Ethics Committee of Lampang Cancer Hospital.

\section{Consent for publication}

Not applicable.

\section{Competing interests}

The authors declare that they have no competing interests.

\section{Publisher's Note}

Springer Nature remains neutral with regard to jurisdictional claims in published maps and institutional affiliations.

\section{Author details}

${ }^{1}$ Graduate School, Chiang Mai University, Chiang Mai, Thailand. ${ }^{2}$ Department of Statistics, Faculty of Science, Chiang Mai University, Chiang Mai, Thailand. 
${ }^{3}$ Division of Radiation Oncology, Department of Radiology, Faculty of Medicine, Chiang Mai University, Chiang Mai, Thailand. ${ }^{4}$ Chiang Mai Cancer Registry, Maharaj Nakorn Chiang Mai Hospital, Faculty of Medicine, Chiang Mai University, Chiang Mai, Thailand. ${ }^{5}$ Northern Thai Research Group of Radiation Oncology (NTRG-RO), Faculty of Medicine, Chiang Mai University, Chiang Mai, Thailand. ${ }^{6}$ Cancer Registry Unit, Lampang Cancer Hospital, Lampang, Thailand. ${ }^{7}$ Center of Excellence in Bioresources for Agriculture, Industry and Medicine, Faculty of Science, Chiang Mai University, Chiang Mai, Thailand.

Received: 23 March 2018 Accepted: 9 September 2018 Published online: 24 September 2018

\section{References}

1. Ferlay J, Shin HR, Bray F, Forman D, Mathers C, Parkin DM. Estimates of worldwide burden of cancer in 2008: GLOBOCAN 2008. Int J Cancer. 2010; 127:2893-917.

2. Ferlay J, Soerjomataram I, Dikshit R, Eser S, Mathers C, Rebelo M, et al. Cancer incidence and mortality worldwide: sources, methods and major patterns in GLOBOCAN 2012. Int J Cancer. 2015;136:E359-86.

3. Fitzmaurice C, Allen C, Barber RM, Barregard L, Bhutta ZA, Brenner $H$, et al. Global, regional, and national cancer incidence, mortality, years of life lost, years lived with disability, and disability-adjusted life-years for 32 cancer groups, 1990 to 2015: a systematic analysis for the global burden of disease study. JAMA Oncology. 2017;3:524-48.

4. Aungkulanon S, Tangcharoensathien V, Shibuya K, Bundhamcharoen K, Chongsuvivatwong V. Post universal health coverage trend and geographical inequalities of mortality in Thailand. Int J Equity Health. 2016;15(190). https://doi.org/10.1186/s12939-016-0479-5.

5. Ministry of Public Health Thailand. Public Health Statistics A.D.2015 (in Thai). http://www.bcnlp.ac.th/ULIB6/dublin.php?ID=13399121403. Accessed 25 Nov 2017

6. Virani S, Bilheem S, Chansaard W, Chitapanarux I, Daoprasert K, Khuanchana $S$, et al. National and subnational population-based incidence of cancer in Thailand: assessing cancers with the highest burdens. Cancers (Basel). 2017; 9:1-27. https://doi.org/10.3390/cancers9080108.

7. Imsamran W, Chaiwerawattana A, Wiangnon S, Pongnikorn D, Suwanrungrung K, Sangrajrang S, et al. Cancer in Thailand. Vol. VIII, 2010-2012. Bangkok: National Cancer Institute; 2015.

8. Benjakul S, Termsirikulchai L, Hsia J, Kengganpanich M, Puckcharern H,

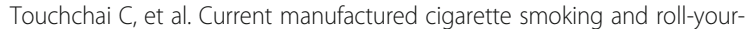
own cigarette smoking in Thailand: findings from the 2009 global adult tobacco survey. BMC Public Health. 2013;13:277. https://doi.org/10.1186/ 1471-2458-13-277.

9. Bumroongkit K, Rannala B, Traisathit $P$, Srikummool M, Wongchai $Y$, Kangwanpong D. TP53 gene mutations of lung cancer patients in upper northern Thailand and environmental risk factors. Cancer Genet Cytogenet. 2008;185:20-7.

10. Jinsart W, Mitmark B. A GIS model for PM10 exposure from biomass burning in the north of Thailand. Appl Environ Res. 2017;39:77-87.

11. Kowsuvon N, Sangawongse S. Land use changes tendency and environmental quality indicators development for air and water pollutions monitoring in Chiang Mai comprehensive plans boundary, Thailand. PSAKU Int J Interdisciplinary Res. 2016;5:60-70.

12. Nakachi $K$, Limtrakul $P$, Sonklin $P$, Jarern $C T$, Lipigorngoson $S$, Arai $K$, et al. Risk factors for lung cancer among northern Thai women: epidemiological, nutritional, serological, and bacteriological surveys of residents in high-and low-incidence areas. Cancer Sci. 1999;90:1187-95.

13. Permsuwan U, Niamhun N, Tanatip N, Thongprasert S. Epidermal growth factor receptor mutation testing in Thailand: a cost-utility analysis. Value Health Reg Issues. 2014;3:39-43.

14. Sukitpaneenit M, Kim Oanh NT. Satellite monitoring for carbon monoxide and particulate matter during forest fire episodes in northern Thailand. Environ Monit Assess. 2014;186:2495-504.

15. Thongprasert S, Permsuwan U. Crizotinib treatment for advanced non-smallcell lung cancer patients: a budget impact analysis based in Thailand. Curr Med Res Opin. 2017;33:955-61.

16. Wattananikorn $K$, Emharuthai $S$, Wanaphongse $P$. A feasibility study of geogenic indoor radon mapping from airborne radiometric survey in northern Thailand. Radiat Meas. 2008;43:85-90.
17. Wiwatanadate P. Lung cancer related to environmental and occupational hazards and epidemiology in Chiang Mai, Thailand. Genes and Environment. 2011;33:120-7

18. Wodarz D, Zauber AG. Cancer: risk factors and random chances. Nature. 2015;517:563-4.

19. Benach J, Yasui Y. Geographical patterns of excess mortality in Spain explained by two indices of deprivation. J Epidemiol Community Health. 1999;53:423-31.

20. Macintyre S, Ellaway A. Neighborhoods and health: an overview. In: Ichiro K, Lisa FB, editors. Neighborhoods and health. Edn. New York: Oxford University; 2003. p. 20-42.

21. Mackenbach JP, Kunst AE, Looman C. Cultural and economic determinants of geographical mortality patterns in the Netherlands. J Epidemiol Community Health. 1991;45:231-7.

22. Chen W, Zheng R, Zeng H, Zhang S. Epidemiology of lung cancer in China. Thoracic Cancer. 2015;6:209-15.

23. Kodama K, Nakadaira H, Endoh K, Yamamoto M. Geographic clustering patterns in mortality from biliary tract cancer in Japan. Cancer Sci. 1998;89:6-11.

24. Milner J, Shrubsole C, Das P, Jones B, Ridley I, Chalabi Z, et al. Home energy efficiency and radon related risk of lung cancer: modelling study. $\mathrm{Br}$ Med J. 2014;348:1-12. https://doi.org/10.1136/bmj.f7493.

25. Pavia M, Bianco A, Pileggi C, Angelillo IF. Meta-analysis of residential exposure to radon gas and lung cancer. Bull World Health Organ. 2003;81:732-8.

26. Youlden DR, Cramb SM, Baade PD. The international epidemiology of lung Cancer: geographical distribution and secular trends. J Thorac Oncol. 2008;3: 819-31.

27. Pengchai P, Chantara S, Sopajaree K, Wangkarn S, Tengcharoenkul U, Rayanakorn M. Seasonal variation, risk assessment and source estimation of PM 10 and PM10-bound PAHs in the ambient air of Chiang Mai and Lamphun, Thailand. Environ Monit Assess. 2009;154:197-218.

28. Long X, Tie X, Cao J, Huang R, Feng T, Li N, et al. Impact of crop field burning and mountains on heavy haze in the North China plain: a case study. Atmos Chem Phys. 2016;16:9675-91.

29. Wiriya W, Prapamontol T, Chantara S. PM10-bound polycyclic aromatic hydrocarbons in Chiang Mai (Thailand): seasonal variations, source identification, health risk assessment and their relationship to air-mass movement. Atmos Res. 2013;124:109-22.

30. Suwanwaree P, Phayungwiwatthanakoon C, Dasananda S. Application of new MODIS-based aerosol index for air pollution severity assessment and mapping in upper northern Thailand. Environ Asia. 2014;7:133-41.

31. Pope CA, Burnett RT, Thun MJ, Calle EE, Krewski D, Ito K, et al. Lung Cancer, cardiopulmonary mortality, and long-term exposure to fine particulate air pollution. JAMA. 2002;287:1132-41.

32. Zhang Y, Mo J, Weschler CJ. Reducing health risks from indoor exposures in rapidly developing urban China. Environ Health Perspect. 2013:121:751-5.

33. Chien $\mathrm{C}-\mathrm{R}, \mathrm{Chen} \mathrm{TH}-\mathrm{H}$. A Bayesian model for age, period, and cohort effects on mortality trends for lung cancer, in association with gender-specific incidence and case-fatality rates. J Thorac Oncol. 2009;4:167-71.

34. Devesa SS, Bray F, Vizcaino AP, Parkin DM. International lung cancer trends by histologic type: male: female differences diminishing and adenocarcinoma rates rising. Int J Cancer. 2005;117:294-9.

35. Puigpinós-Riera R, Marí-Dell'Olmo M, Gotsens M, Borrell C, Serral G, Ascaso $\mathrm{C}$, et al. Cancer mortality inequalities in urban areas: a Bayesian small area analysis in Spanish cities. Int J Health Geogr. 2011;10:6. https://doi.org/10. 1186/1476-072X-10-6.

36. Ramis-Prieto R, García-Pérez J, Pollán M, Aragonés N, Pérez-Gómez B, López-Abente G. Modelling of municipal mortality due to haematological neoplasias in Spain. J Epidemiol Community Health. 2007:61:165-71.

37. Singh GK, Williams SD, Siahpush M, Mulhollen A. Socioeconomic, ruralurban, and racial inequalities in US cancer mortality: part I-all cancers and lung cancer and part II-colorectal, prostate, breast, and cervical cancers. J Cancer Epidemiol. 2011;2011:1-27. https://doi.org/10.1155/2011/107497.

38. Meza JL. Empirical Bayes estimation smoothing of relative risks in disease mapping. J Statist Plann Inference. 2003;112:43-62.

39. Alhdiri MA, Samat NA, Mohamed Z. Risk estimation for lung Cancer in Libya: analysis based on standardized morbidity ratio, Poisson-gamma model, BYM model and mixture model. Asian Pac J Cancer Prev. 2017:18:673-9. https://doi.org/10.22034/APJCP.2017.18.3.673. 
40. Clayton D, Kaldor J. Empirical Bayes estimates of age-standardized relative risks for use in disease mapping. Biometrics. 1987;43:671-81.

41. López-Abente G, Aragonés N, Pérez-Gómez B, Pollán M, García-Pérez J, Ramis $\mathrm{R}$, et al. Time trends in municipal distribution patterns of cancer mortality in Spain. BMC Cancer. 2014;14(535). https://doi.org/10.1186/14712407-14-535.

42. Riebler A, Sørbye SH, Simpson D, Rue H. An intuitive Bayesian spatial model for disease mapping that accounts for scaling. Stat Methods Med Res. 2016; 25:1145-65.

43. Pongnikorn D, Daoprasert K, Waisri N, Laversanne M, Bray F. Cancer incidence in northern Thailand: results from six population-based cancer registries 19932012. Int J Cancer. 2017;142:1767-75. https://doi.org/10.1002/ijc.31203.

44. Lawson AB. Bayesian disease mapping: hierarchical modeling in spatial epidemiology. New York. United States: Chemical Rubber Company press; 2013.

45. Besag J, York J, Mollié A. Bayesian image restoration, with two applications in spatial statistics. Ann Inst Stat Math. 1991:43:1-20.

46. Lawson AB, Browne WJ, CLV R. Disease mapping with WinBUGS and MLwiN. West Sussex. England: John Wiley \& Sons; 2003.

47. BUGS. OpenBUGS version 3.2.3. http://www.openbugs.net/w/FrontPage. Accessed 25 Nov 2017.

48. The Comprehensive R Archive Network. R version 3.4.1. https://cran.rproject.org/. Accessed 25 Nov 2017.

49. Gerber F, Furrer R. Pitfalls in the implementation of Bayesian hierarchical modeling of areal count data: an illustration using BYM and Leroux models. J Stat Softw. 2015:63:1-32. https://doi.org/10.18637/jss.v063.c01.

50. Spiegelhalter DJ, Best NG, Carlin BP, Van Der Linde A. Bayesian measures of model complexity and fit. Stat Methodol Series B. 2002;64:583-639.

51. QGIS. Quantum Geographic Information System program version 2.8.1. https://qgis.org/en/site/. Accessed 25 Nov 2017.

52. United Nations Office for the Coordination of Humanitarian Affairs - Regional Office for Asia and the Pacific. Thai district boundaries. https:/data.humdata. org/dataset/thailand-administrative-boundaries. Accessed 27 Nov 2017.

53. Trama A, Boffi R, Contiero P, Buzzoni C, Pacifici R, Mangone L, et al. Trends in lung cancer and smoking behavior in Italy: an alarm bell for women. Tumori J. 2017;103:543-50.

54. Sooktawee S, Patpai A, Kongsong R, Boonyapitak S, Piemyai N. Visualization and interpretation of PM10 monitoring data related to causes of haze episodes in northern Thailand. Appl Environ Res. 2015;37:33-48.

55. Kristina SA, Endarti D, Thavorncharoensap M. Burden of cancer attributable to tobacco smoking in member countries of the Association of Southeast Asian Nations (ASEAN), 2012. Cancer Epidemiol. 2016;44:84-90.

56. Simarak S, DE Jong UW, Breslow N, Dahl CJ, Ruckphaopunt K, Scheelings $P$, et al. Cancer of the oral cavity, pharynx/larynx and lung in North Thailand: case-control study and analysis of cigar smoke. Br J Cancer. 1977;36:130-40.

57. Reichart PA, Philipsen HP, Mohr U, Geerlings H, Srisuwan S. Miang chewing in northern Thai villagers. Trop Geogr Med. 1988;40:39-44.

58. Lopez-Abente G, Aragones N, Ramis R, Hernandez-Barrera V, Perez-Gomez B, Escolar-Pujolar A, et al. Municipal distribution of bladder cancer mortality in Spain: possible role of mining and industry. BMC Public Health. 2006;6(17). https://doi.org/10.1186/1471-2458-6-17.

Ready to submit your research? Choose BMC and benefit from:

- fast, convenient online submission

- thorough peer review by experienced researchers in your field

- rapid publication on acceptance

- support for research data, including large and complex data types

- gold Open Access which fosters wider collaboration and increased citations

- maximum visibility for your research: over $100 \mathrm{M}$ website views per year

At BMC, research is always in progress.

Learn more biomedcentral.com/submissions 